\section{Publisher Correction: \\ Indo-Pacific Walker \\ circulation drove \\ Pleistocene African \\ aridification}

https://doi.org/10.1038/s41586-021-04193-9

Published online: 23 February 2022

Correction to: Nature https://doi.org/10.1038/s41586-021-03896-3

Published online 27 October 2021

Check for updates

H. J. L. van der Lubbe, I. R. Hall, S. Barker, S. R. Hemming, T. F. Baars,

A. Starr, J. Just, B. C. Backeberg \& J. C. A. Joordens

Original Fig. 3
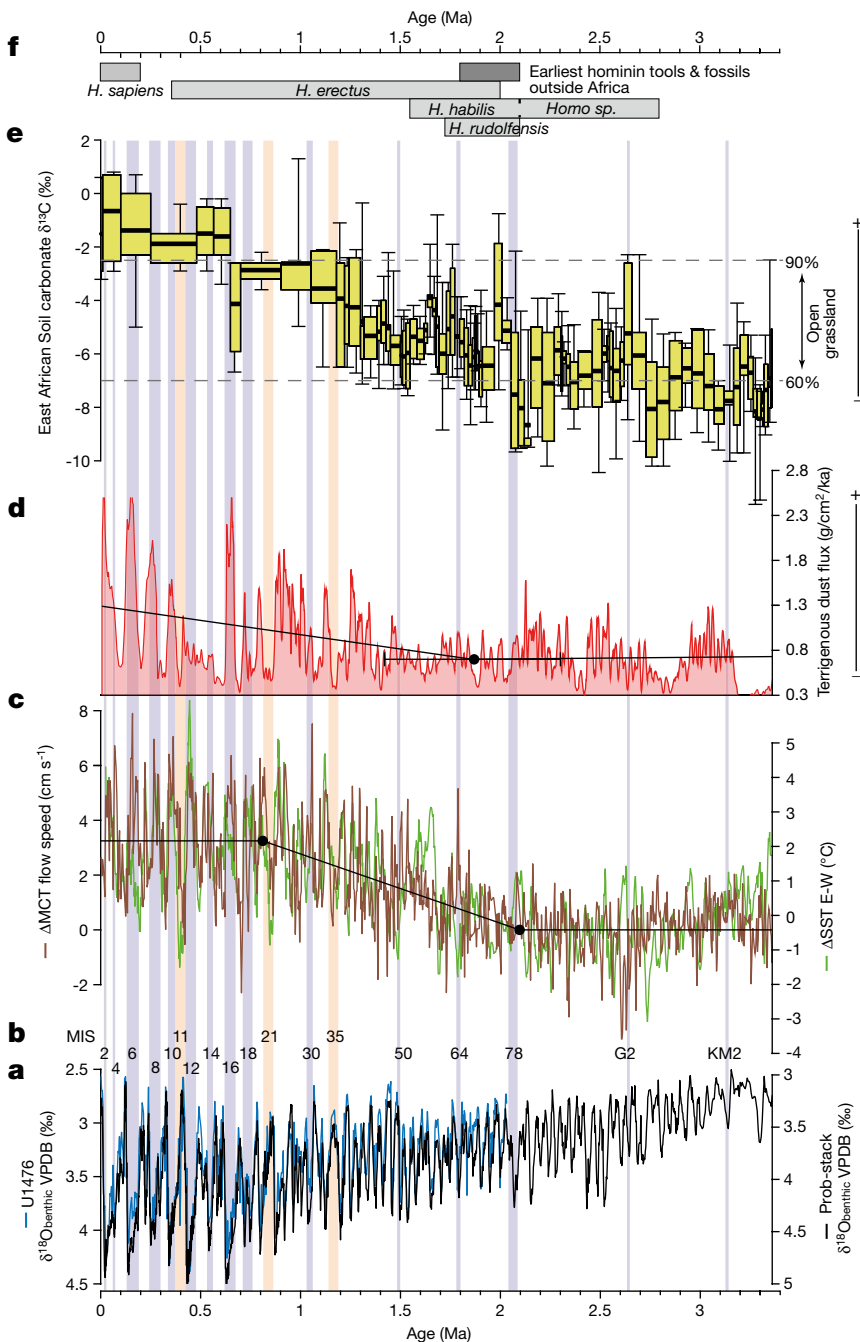

In this Article, a processing error led to the wrong versions of Fig. 3 and Extended Data Fig. 4 being published. Figure 3 e did not include the entirety of the eastern Africa soil carbonate $\delta^{13} \mathrm{C}$ database as compiled by ref. ${ }^{13}$. Fig. 3 of the original Article has been corrected, and Fig. 1 of this Amendment shows the original and corrected Fig. 3 side by side, for transparency. In the Methods section of the original Article, there are further details about how this record has been produced. The last paragraph of the Methods has been corrected; the original text was: "On the basis of ref. ${ }^{13}$, time series of $\delta^{13} \mathrm{C}$ values from soil carbonate were combined for the Omo-Turkana Basin and the southern Kenyan-Tanzanian sites using their medians, and interquartile ranges using six-data-point bins." Furthermore, the original version of Extended Data Fig. 4 did not display data from eastern African hominin site Afar; the figure and caption have been updated accordingly, and the original and corrected versions are shown as Fig. 2 to this Amendment. These changes do not alter any inferences drawn from the data. These errors have been corrected in the online version of the Article.

The Author(s), under exclusive licence to Springer Nature Limited 2022
Corrected Fig. 3

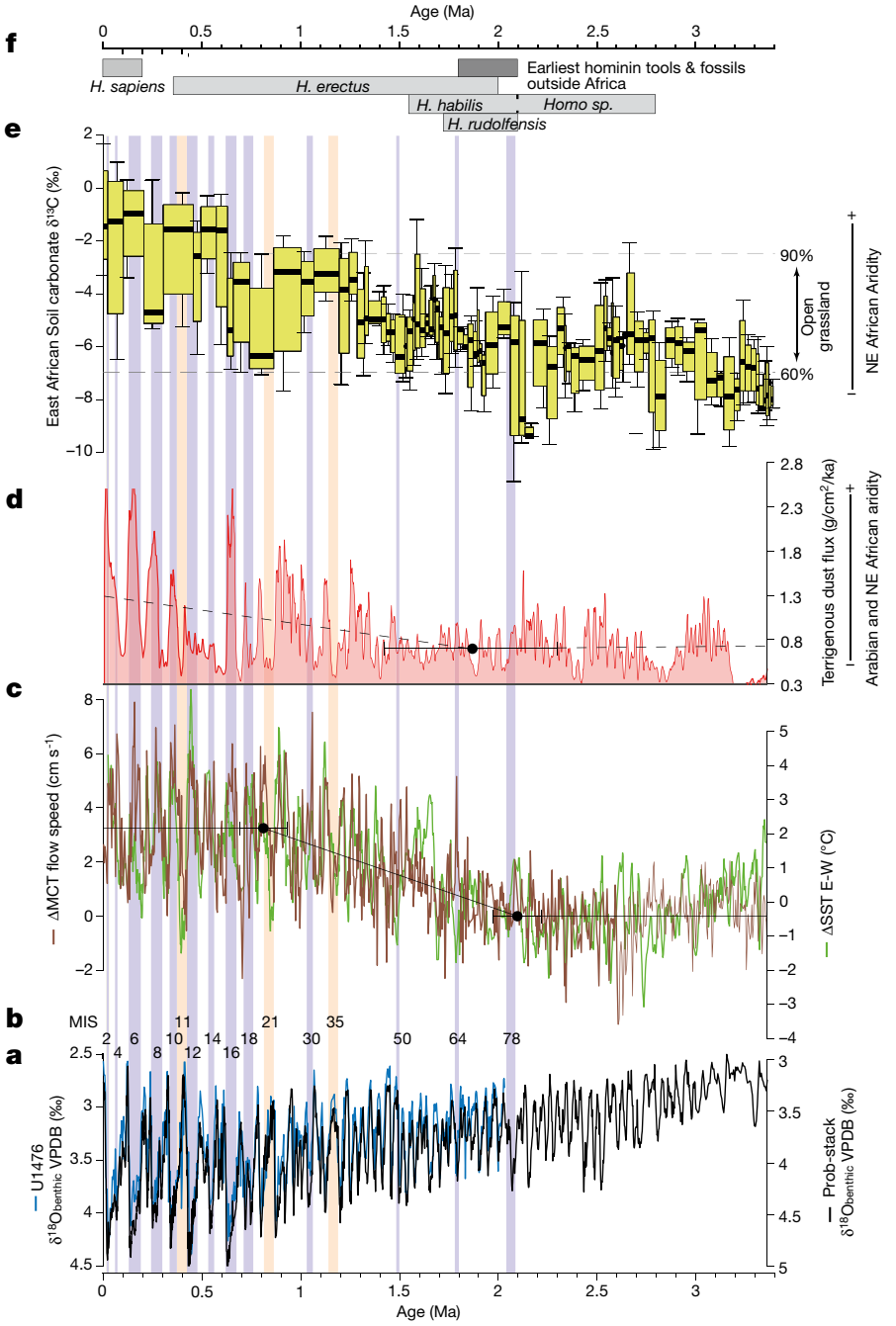

Fig. 1| This figure shows the original and corrected Fig. 3 of the original Article. 


\section{Corrections \& amendments}

Original Extended Data Fig. 4

Mean (2000-2012) minus mean (1979-1999)

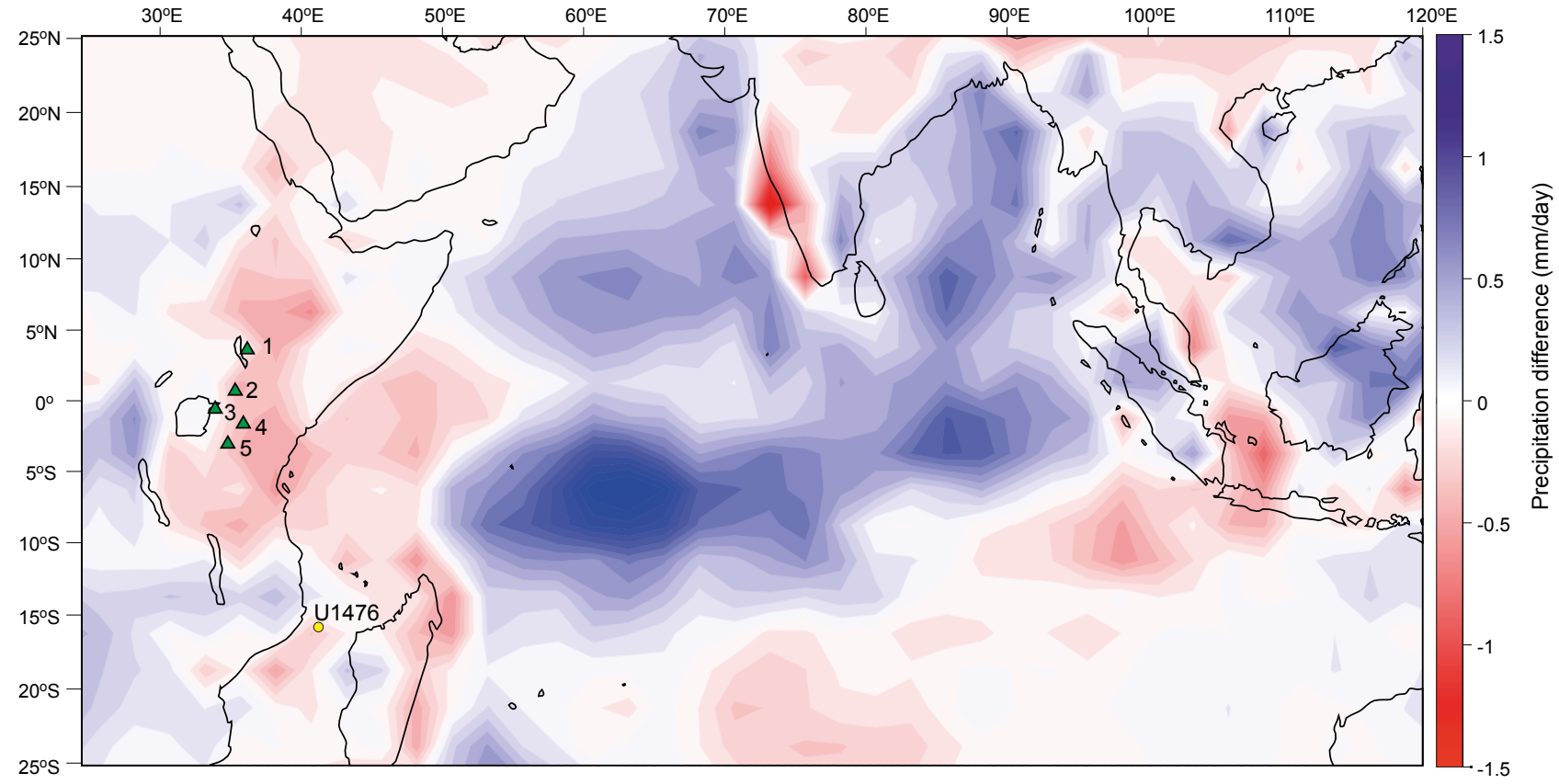

Corrected Extended Data Fig. 4

Mean (2000-2012) minus mean (1979-1999)

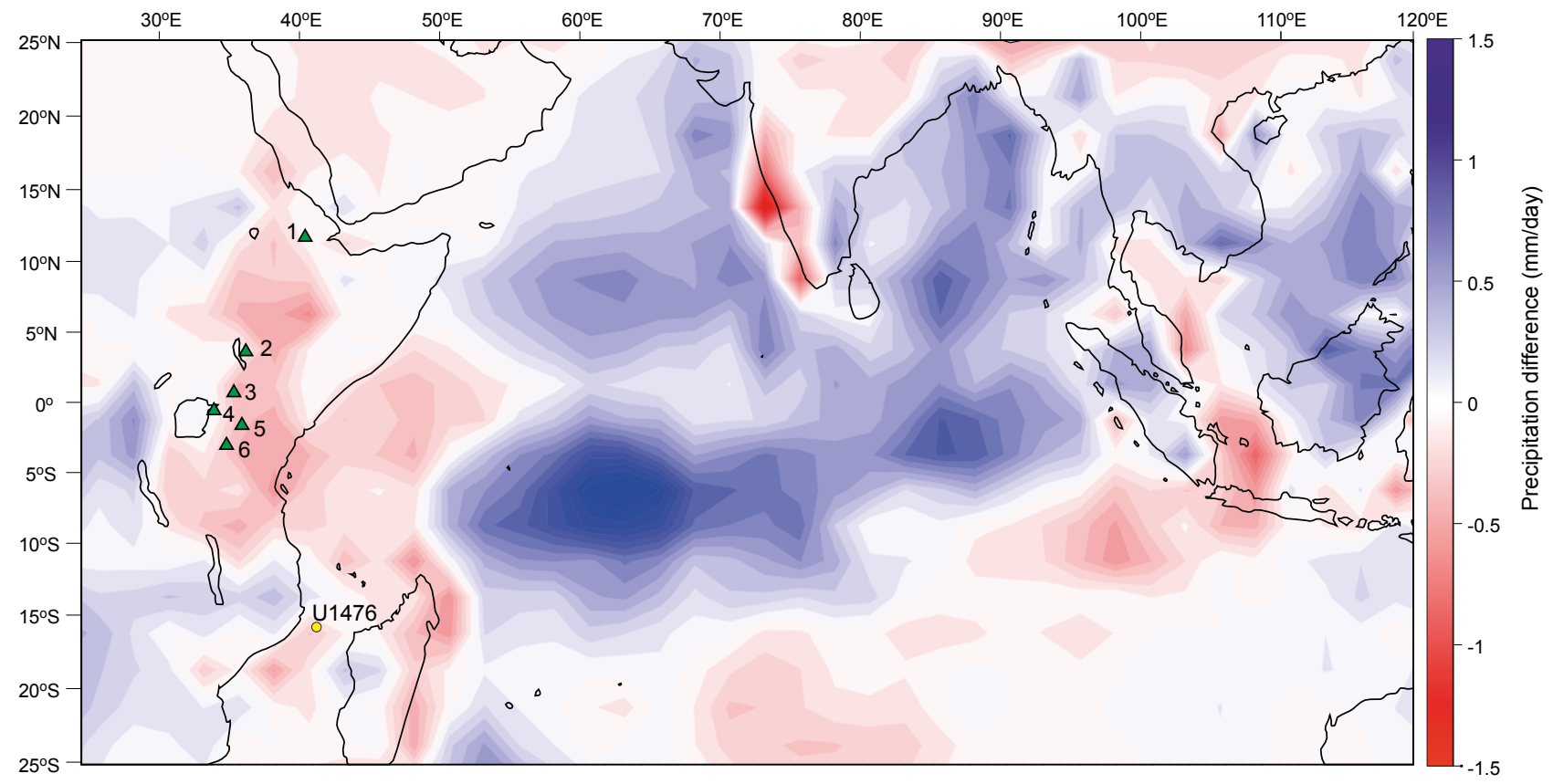

Fig. 2 | This figure shows the original and corrected Extended Data Fig. 4 of the original Article. 